\title{
The Regional Distribution and Determinants of Myocardial Blood Flow during Asphyxia in the Fetal Lamb
}

\author{
J. M. DAVIES ${ }^{(23)}$ AND W. A. TWEED \\ Department of Anaesthesia, Foothills Hospital at the University of Calgary, Calgary, Alberta, Canada [J.M.D.] \\ and Department of Anaesthesia, University Hospital, University of Western Ontario, \\ London, Ontario, Canada [W.A.T.]
}

\section{Summary}

The syndrome of hypoxemia-related myocardial dysfunction in the newborn is generally associated with severe intrapartum asphyxia. We investigated the changes in total and regional distribution of myocardial blood flow (MBF) that occur during asphyxia and the factors that regulate MBF, in the chronically prepared, near term, fetal lamb. Studies were done in the awake, physiologically stable state $36-72 \mathrm{~h}$ after surgical preparation. In utero asphyxia was produced by partial cord occlusion and blood flow to fetal organs was measured by the radioactive microsphere technique. A complete set of control measurements was made, and then an occlusion loop was inflated to partially occlude the umbilical vessels. After 30-60 min of partial occlusion, all measurements were repeated. The third set of measurements was made after release of the occlusion loop. Six animals were studied and 17 sets of measurements obtained.

Partial umbilical cord constriction produced a progressive asphyxia and acidosis. Cardiac output was severely depressed, although the increase in percentage of cardiac output directed to the myocardium (\%F) was very significant. Release resulted in improved cardiac output and $\mathrm{O}_{2}$ and $\mathrm{CO}_{2}$ exchange, although the metabolic acidosis was worse. No change occurred in the intramyocardial distribution of MBF during asphyxia or recovery. Total MBF was not significantly increased during asphyxia.

Multiple linear regression analysis indicated that arterial oxygen saturation $\left(\mathrm{SaO}_{2}\right)$ and heart rate were statistically significant predictor variables for absolute MBF, accounting for about $\mathbf{4 5 \%}$ of the variation in MBF. Further analysis determined that mean arterial blood pressure, $\mathrm{pH}, \mathrm{Po}_{2}$, and $\mathrm{SaO}_{2}$ were all statistically significant univariate predictors of $\mathrm{MBF}$ as $\% \mathrm{~F}$, but only $\mathrm{SaO}_{2}$ was a statistically significant multivariate predictor, accounting for about $82 \%$ of the variation in $\% \mathbf{F}$.

We conclude that redistribution of a reduced cardiac output during cord occlusion is a major protective mechanism to maintain perfusion of vital organs. This redistribution is due in part to obstruction of placental blood flow, and probably also in part to chemoreceptor mediated circulatory reflexes, via $\mathrm{O}_{2}$ receptors. No intramyocardial redistribution of coronary perfusion was observed during asphyxia; thus, this study provides no evidence for regional myocardial ischemia as a complication of severe intrapartum asphyxia.

\section{Abbreviations}

MBF, myocardial blood flow

F, flow

W, weight

RFI, relative flow index
HR, heart rate

MABP, mean arterial blood pressure

$\mathrm{SaO}_{2}$, arterial oxygen saturation

The syndrome of hypoxemia-related myocardial dysfunction in the newborn has been repeatedly described in the clinical literature $(3,14,19)$. Affected infants are more likely to have suffered peripartum asphyxia or hypoglycemia $(2,4)$, and to have had higher birth weights $(9,20)$. Clinically, they exhibit cardiorespiratory failure and a murmur of atrioventricular valvular insufficiency $(2,3,19,20)$. Evidence of myocardial ischemia during the fulminant period of heart failure has been obtained from biochemical (17), electrocardiographic $(4,10,19,20)$ and radiological studies [cineangiography $(2)$ and thallium myocardial imaging (10)].

Pathological studies of infants who died in the peripartum period describe focal arterial necrosis and focal and diffuse myocardial necrosis, including papillary muscle necrosis $(7,9$, $20)$. It is likely that the clinical and pathological pictures are related. Although the pathological syndrome of myocardial necrosis in the newborn was originally thought to be due to anatomic occlusion of the coronary arteries (8), recent work suggests that disturbances of myocardial blood flow $(9,10)$ and metabolism (2) are more probable pathophysiological mechanisms.

Infants with hypoxemia-related myocardial dysfunction during the first $48 \mathrm{~h}$ of life can be divided by clinical characteristics into two groups: those with severe prenatal asphyxia (hypoxemia and acidemia) who develop cardiogenic shock or heart failure, cyanosis, and tricuspid insufficiency in the immediate postnatal period (Type I); and those who, without evidence of prenatal asphyxia, develop postnatal heart failure and respiratory distress at $12-36 \mathrm{~h}$ with signs of global myocardial ischemia (Type II) (15).

The chronically prepared, near term, fetal lamb was used to study myocardial perfusion during severe prenatal asphyxia. The changes in total and regional distribution of MBF and the factors that regulate MBF were studied during asphyxia. The object of this study was to identify abnormalities of myocardial perfusion that might contribute to the syndrome of hypoxemia-related myocardial dysfunction.

\section{MATERIALS AND METHODS}

We studied six near-term fetal lambs estimated to be $130-140$ days gestation. Surgical preparation was done under halothane/ oxygen general anesthesia, with controlled ventilation via an endotracheal tube. The ewe was placed in the supine position and femoral arterial and venous catheters inserted. Through a 
midline abdominal approach, a small hysterotomy was made to expose the fetal limbs. A hindlimb was delivered, and femoral arterial and venous catheters $(0.86 \mathrm{~mm}$ ID, $1.27 \mathrm{~mm} \mathrm{OD})$ were advanced to the descending aorta and inferior vena cava. A forelimb was then delivered, and a similar axillary artery catheter was advanced to the common brachiocephalic trunk. An inflatable cord occlusion loop was gently placed around the umbilical cord. The incisions were closed and all catheters brought subcutaneously to a pocket on the ewe's flank. Prophylactic antibiotics were administered to both mother and fetus daily until the studies were complete (penicillin G: 1 million IU to the ewe, 500,000 IU to the fetus; gentamycin: $60 \mathrm{mg}$ to the ewe, $20 \mathrm{mg}$ to the fetus).

Studies were performed 36 to $72 \mathrm{~h}$ after surgical preparation. In the laboratory, the ewe stood quietly in a cart, and was allowed hay and water ad libitum and a companion. Fetal and maternal arterial blood pressures and fetal venous pressures were continuously recorded with Statham P23 pressure transducers and a Hewlett-Packard dynograph. Maternal femoral and fetal ascending aortic blood gases were measured with a Corning 165 blood gas analyzer at $37^{\circ} \mathrm{C}$. Per cent fetal oxygen saturation was calculated by the equation of Meschia et al. (16): $\log \mathrm{Po}_{2}=\log$ $\left(\mathrm{PO}_{2}\right) 50,7.4-K_{2}(\mathrm{pH} 7.4)+0.368 \log S /(100-S)$ in which $\left(\mathrm{Po}_{2}\right) 50,7.4$ is the oxygen tension at which the hemoglobin is half saturated at $\mathrm{pH}$ of $7.4, K_{2}$ and 0.368 are two coefficients, and $S$ is the per cent saturation of hemoglobin with oxygen. The average values of $K_{2}$ and $\log \left(\mathrm{Po}_{2}\right)$ 50,7.4 for fetal hemoglobin in the lamb are 0.532 and 1.213 , respectively. Maternal rectal temperature was monitored and averaged $38.5^{\circ} \mathrm{C}$.

Fetal myocardial and other organ blood flows were measured by the microsphere technique, using $15-\mu \mathrm{m}$ diameter microspheres labeled with $\gamma$-emitting ${ }^{141} \mathrm{Ce},{ }^{51} \mathrm{Cr}$, or ${ }^{85} \mathrm{Sr}$ (3M Company). For each measurement, approximately 1 million spheres were injected into the inferior vena cava over $30 \mathrm{sec}$. Reference arterial blood samples were withdrawn at a fixed rate, $1.94 \mathrm{ml} /$ min, from the brachiocephalic and descending aortic catheters, starting $30 \mathrm{sec}$ before, during, and $2 \mathrm{~min}$ after, microsphere injection (3-min total collection time).

After the ewe had rested quietly in the laboratory for $1-2 \mathrm{~h}$, a complete set of laboratory, hemodynamic, and blood gas mesurements were made (Flow 1). Then the umbilical cord was partially occluded by inflating the implanted occlusion loop. Continuous recording of the fetal arterial blood pressure (and derived heart rate) was done until hypertension and bradycardia were observed: Occlusion was continued until the fetal $\mathrm{pH}$ reached and stabilized at 7.1-7.2, and a second set of complete measurements was made (Flow 2). With this method (cord occlusion), asphyxia and acidosis are progressive, and in order not to kill the fetus, it was necessary to release the loop after the second set of measurements was made. The third set of measurements was made about 60 min after release of the cuff (Flow 3 ).

At the end of the experiment, mother and fetus were painlessly killed with intravenous sodium pentothal and saturated $\mathrm{KCl}$ solution. The fetus was autopsied to validate catheter placement, and then fetal organs were weighed and ashed for radionuclide counting. Radionuclide levels in the blood samples and ashed tissue samples were counted in a Searle $\gamma$ well counter. If microspheres are homogeneously distributed in the arterial blood supplying an organ, and are completely removed from the blood during passage of the blood through the organ, then the following equation calculates blood flow to that organ: $F=F a \times i$ organ/ $i$ arterial, where $F=$ organ blood flow $(\mathrm{ml} / 100 \mathrm{~g} / \mathrm{min}) ; F a=$ withdrawal rate of the reference arterial blood sample $(\mathrm{ml} / \mathrm{min})$; $i$ organ $=$ microsphere content of the organ tissue $(\mathrm{cpm} / 100 \mathrm{~g}) ;$ and $i$ arterial $=$ microsphere content of the total reference arterial blood sample (cpm).

In order to determine regional distribution of myocardial blood flow, the fetal heart was divided in a systematic method. The left and right ventricles were cut into three transverse slices, after first removing the extreme apex, the atria, and the great vessels and trimming off epicardial fat and visible vessels. Then each slice was cut into three segments, representing the left ventricle, right ventricle, and septum. Next, each segment was divided into two layers, endocardium and epicardium. The heart so cut yielded $3 \times 3 \times 2=18$ separate tissue samples, which were weighed and then counted for microsphere radioactivity.

For computer calculation of myocardial blood flow distribution, the data for microsphere radioactivity and weight for each myocardial tissue sample $(i)$ was organized into a three-dimensional matrix. Each cell in the matrix contains two pieces of data, $\% \mathrm{~F}$ and $\% \mathrm{~W}$. The ratio of these, $\% \mathrm{~F} / \% \mathrm{~W}$, defines the RFI for each sample.

$$
\mathrm{RFI}=\frac{\% \mathrm{~F}}{\% \mathrm{~W}}=\frac{\mathrm{cpm}_{i} / \mathrm{cpm}_{T}}{\mathrm{~W}_{i} / \mathrm{W}_{T}}=\frac{\mathrm{cpm}_{i} / \mathrm{W}_{i}}{\mathrm{cpm}_{T} / \mathrm{W}_{T}}
$$

The RFI is a dimensionless index of homogeneity of myocardial perfusion, relating microsphere density in the sample of interest $(i)$ to average microsphere density in the total organ $(T)$; that is, the RFI defines the ratio between the blood flow to each sample and the average organ flow.

Since the values for $\% \mathrm{~F}$ and $\% \mathrm{~W}$ can be added along any axis, the matrix can be reduced to describe $\% \mathrm{~F}, \% \mathrm{~W}$, and RFI in any of three planes: vertical, circumferential, or transmural; or in any selected region. The ratio between flows for any two regions, e.g. endocardial/epicardial ratio, is the ratio of the RFI values for those regions. Also, if the average coronary blood flow $(f)$ for the whole heart is known, the absolute flow to any region can be simply calculated as $f \times$ RFI.

\section{RESULTS}

The results are presented from studies in six animals of gestational age of 130-140 days and average weight of $3.60 \mathrm{~kg}$, including placenta. Measurements during asphyxia were obtained in six animals and after partial re-oxygenation in five animals.

Table 1 describes the hemodynamic, blood gas, cardiac output, and MBF data for the three sets of measurements. Partial umbilical cord constriction produced a progressive asphyxia and acidosis. Release resulted in improved $\mathrm{O}_{2}$ and $\mathrm{CO}_{2}$ exchange, although the metabolic acidosis was worse, probably because of washout of acid metabolites from carcass and muscle. The characteristic hypertensive and bradycardic response to asphyxia was observed, with a return to baseline arterial pressure and heart rate during recovery from the asphyxia. Cardiac output was severely depressed, and although absolute myocardial blood flow was not significantly increased, the increase in percentage of

Table 1. Hemodynamic and blood gas measurements in the fetal lamb during control, partial asphyxia, and recovery*

\begin{tabular}{llllc}
\hline & $\begin{array}{c}\text { Control } \\
(n=6)\end{array}$ & $\begin{array}{c}\text { Asphyxia } \\
(n=6)\end{array}$ & $\begin{array}{c}\text { Recovery } \\
(n=5)\end{array}$ & $P$ value \\
\hline $\begin{array}{l}\mathrm{MBF} \\
\quad(\mathrm{ml} / \mathrm{g} / \mathrm{min})\end{array}$ & $2.03 \pm 0.44$ & $2.81 \pm 1.69$ & $1.84 \pm 0.48$ & $\mathrm{NS}$ \\
$\mathrm{Cardiac}$ output & $344 \pm 34$ & $154 \pm 44$ & $298 \pm 77$ & $<0.001$ \\
$\quad(\mathrm{ml} / \mathrm{kg} / \mathrm{min})$ & & & & \\
$\% \mathrm{~F}$ & $2.62 \pm 0.56$ & $7.80 \pm 2.43$ & $4.46 \pm 2.32$ & $<0.01$ \\
$\mathrm{HR}$ & $148 \pm 17$ & $101 \pm 29$ & $152 \pm 36$ & $<0.025$ \\
$\mathrm{MABP}$ & $60.8 \pm 4.8$ & $82.3 \pm 7.7$ & $73.2 \pm 10.2$ & $<0.001$ \\
$\mathrm{pH}$ & $7.39 \pm 0.03$ & $7.12 \pm 0.04$ & $7.10 \pm 0.08$ & $<0.001$ \\
$\mathrm{PCO}_{2}$ & $40.3 \pm 3.2$ & $55.6 \pm 10.0$ & $45.7 \pm 4.9$ & $<0.01$ \\
$\mathrm{PO}_{2}$ & $20.2 \pm 3.4$ & $17.5 \pm 2.2$ & $23.5 \pm 4.5$ & $<0.05$ \\
$\mathrm{SaO}_{2}$ & $62.2 \pm 10.8$ & $32.2 \pm 8.5$ & $49.0 \pm 11.7$ & $<0.001$ \\
\hline
\end{tabular}

* Comparison of hemodynamic and blood gas measurements in the fetal lamb during normoxia, partial asphyxia (by umbilical cord constriction), and recovery (by umbilical cord release). All values shown are mean \pm SD. Statistical analysis is by one-way analysis of variance. NS, not significant. 
cardiac output directed to the myocardium (\%F) was very significant $(P>0.01)$.

Table 2 illustrates the regional distribution of MBF for the three sets of measurements, calculated by the relative flow index method. A significant heterogeneity of perfusion is evident in the control state, with the endocardium significantly better perfused than the epicardium. This pattern is preserved unchanged during asphyxia and recovery, with no evidence of changes in either circumferential or transmural distribution of myocardial perfusion.

In an attempt to define the factors that are significant predictors of MBF, multiple linear regression analysis was applied to the data. The independent variables chosen for analysis were $\mathrm{HR}, \mathrm{MABP}, \mathrm{pH}, \mathrm{PCO}_{2}, \mathrm{PO}_{2}$, and $\mathrm{SaO}_{2}$, and the dependent variables were MBF expressed both as absolute flow $(\mathrm{ml} / \mathrm{g} / \mathrm{min})$ and $\% \mathrm{~F}$.

Only $\mathrm{SaO}_{2}$ and $\mathrm{HR}$ were statistically significant predictor variables for absolute MBF and the least squares best fit equation was: $\mathrm{MBF}=0.016 \mathrm{HR}-0.05 \mathrm{SaO}_{2}+2.45$ where $r=0.67, r^{2}=$ 0.45 , and $P<0.025$.

This suggests that about $45 \%$ of the variation in absolute MBF in these experiments can be "explained" by the relationship to $\mathrm{HR}$ and $\mathrm{SaO}_{2}$.

Although $\mathrm{MABP}, \mathrm{pH}, \mathrm{pO}_{2}$, and $\mathrm{SaO}_{2}$ were all statistically significant univariate predictors of $\mathrm{MBF}$ as per cent cardiac output, only $\mathrm{SaO}_{2}$ was a statistically significant multivariate predictor. The relationship was curvilinear (Fig. 1) and the least squares analysis best fit equation was provided by the reciprocal function: $\% \mathrm{~F}=269.4 / \mathrm{SaO}_{2}-1.45$ where $r=0.91, r^{2}=0.82$, and $P<0.001$.

This suggests that MABP, $\mathrm{pH}$, and $\mathrm{pO}_{2}$ are not true independent predictor variables, but are interdependent with $\mathrm{SaO}_{2}$, and the best fit equation indicates that about $82 \%$ of the variation in $\% \mathrm{~F}$ can be explained by its relationship to $\mathrm{SaO}_{2}$.

\section{DISCUSSION}

Clinical and experimental evidence indicates that the syndrome of myocardial dysfunction in the asphyxiated newborn is the result of a combination of insults: 1) critically reduced arterial oxygen content, 2) focal and diffuse myocardial ischemia, and 3) depletion of myocardial energy substrates, particularly myocardial glycogen, and plasma glucose. Demands for increased cardiac output in the immediate postpartum period, combined with hypoxic pulmonary vasoconstriction, may impose a workload that the compromised heart cannot sustain, with ensuing cardiac failure.

The lamb is the most frequently studied animal model of MBF in the fetus and newborn, although a study in a primate (Macaca mulatta) has been reported (1). MBF in the control, normoxic state was reported to average between 1.45 and $2.0 \mathrm{ml} / \mathrm{g} / \mathrm{min}$ in the fetal lamb $(1,5,11,13,21)$, about twice that of the adult sheep (11). Both flow and cardiac work are higher in the newborn lamb than in the fetus (12).

During hypoxia or asphyxia, MBF has been observed to increase, although the increase in mean MBF during asphyxia was less in our experiments than has been reported by others. Cohn et al. (5) found a $260 \%$ increase in the per cent distribution of cardiac output to the heart during hypoxemia and acidemia; and Peeters et al. (18) reported comparable changes when fetal arterial oxygen content dropped below $2 \mathrm{mM}$. However, our animals were more severely stressed, were considerably more acidotic, and had a pronounced fall in cardiac output. When MBF is calculated as a percentage of cardiac output, the results of all of these experiments are similar. Redistribution of a reduced cardiac output during cord occlusion, although partly a result of obstruction to placental blood flow, is evidently a major protective mechanism to maintain perfusion of vital organs. This implies that potent cardiovascular reflexes are activated during asphyxia, resulting in selective vasoconstriction and bradycardia. The regulation of these reflexes is as yet unknown, although the data from this study suggest that it is chemoreceptor-mediated via $\mathrm{O}_{2}$ receptors. The most significant multivariate determinant for both absolute MBF and redistribution of cardiac output was arterial oxygen saturation in the fetal ascending aorta $\left(\mathrm{SaO}_{2}\right)$. Although both $\mathrm{SaO}_{2}$ and $\mathrm{HR}$ were identified as significantly related to $\mathrm{MBF}$, the regulation of coronary perfusion during asphyxia is still far from understood.

The regional distribution of MBF within the heart has not previously been reported during asphyxia. However, no evidence was found for regional redistribution of MBF or focal myocardial ischemia during asphyxia; in fact, the regional pattern of MBF distribution was preserved unchanged and is similar to that found by Fisher et al. (13). Thus, this study does not implicate regional myocardial ischemia as a complication of severe intrapartum asphyxia.

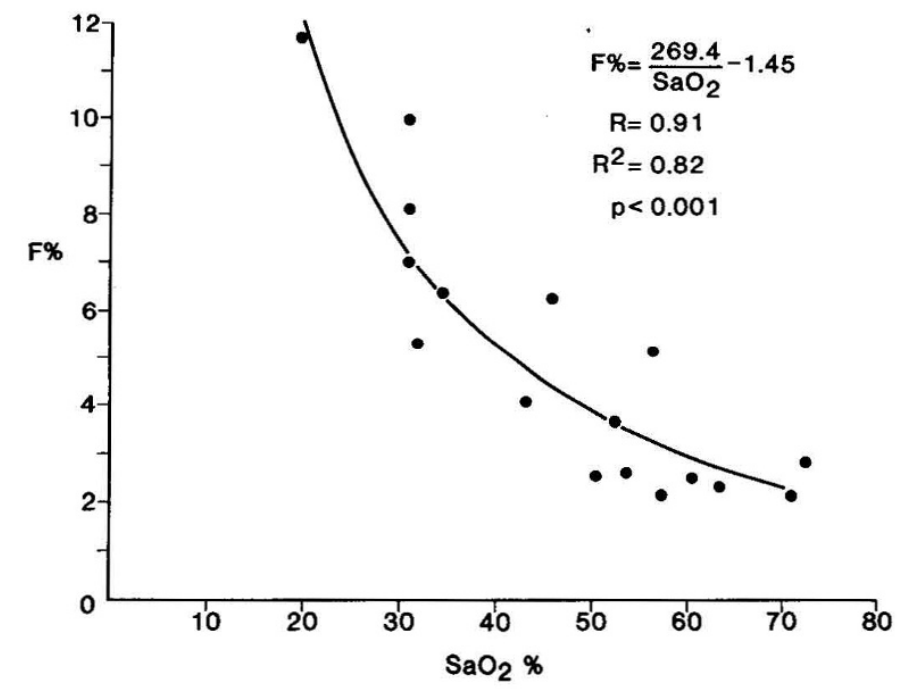

Fig. 1. Relation between ascending aorta oxygen saturation and per cent cardiac output directed to the heart. F\% is per cent of cardiac output directed to the heart, calculated as (flow to the heart/cardiac output) $\times$ 100. The reciprocal function $\left(1 / \mathrm{SaO}_{2}\right)$ was the equation which provided the best fit to the data points with a multiple regression coefficient $(r)$ value of 0.91 . The addition of other potential independent variables, $\mathrm{MABP}, \mathrm{pH}$, and $\mathrm{PaO}_{2}$, to the multiple regression analyses did not significantly improve the correlation.

Table 2. Regional distribution of fetal myocardial blood flow during control, asphyxia, and recovery states*

\begin{tabular}{|c|c|c|c|c|c|c|c|c|}
\hline & \multicolumn{6}{|c|}{ RFI in segments } & \multirow[b]{2}{*}{$P$} & \multirow{2}{*}{$\begin{array}{c}\text { Actual mean } \\
\text { MBF } \\
(\mathrm{ml} / \mathrm{g} / \mathrm{min})\end{array}$} \\
\hline & LV endo & LV epi & RV endo & RV epi & $\begin{array}{c}\text { Left } \\
\text { septum }\end{array}$ & $\begin{array}{c}\text { Right } \\
\text { septum }\end{array}$ & & \\
\hline Control & 1.01 & 0.88 & 1.19 & 1.00 & 0.96 & 1.01 & 0.05 & $2.03 \pm 0.44$ \\
\hline Asphyxia & 1.02 & 0.80 & 1.23 & 0.96 & 1.04 & 1.06 & 0.01 & $2.81 \pm 1.69$ \\
\hline Recovery & 1.07 & 0.80 & 1.16 & 0.96 & 1.03 & 1.05 & 0.05 & $1.84 \pm 0.48$ \\
\hline
\end{tabular}

* Comparison of the regional distribution of MBF in the fetal lamb during control, partial asphyxia (produced by umbilical cord occlusion), and recovery (after umbilical cord release). The RFI for each region describes regional flow as a proportion of mean flow (mean $=1$ ). Actual mean MBF $( \pm S D)$ is shown. Statistical analysis is by one-way analysis of variance. $L V$, left ventricle; RV, right ventricle. 


\section{REFERENCES AND NOTES}

1. Behrman RE, Lees MH, Peterson EN, deLannoy CW, Seeds AE 1970 Distribution of the circulation in the normal and asphyxiated fetal primate. Am J Obstet Gynecol 108:956

2. Bucciarelli RL, Nelson RM, Egan EA II, Eitzman DV, Gessner IH 1977 Transient tricuspid insufficiency of the newborn: a form of myocardial dysfunction in stressed newborns. Pediatrics 59:330

3. Burnard ED, James LS 1961 Failure of the heart after undue asphyxia at birth. Pediatrics 28:545

4. Cabal LA, Devaskar U, Siassi B, Hodgman JE, Emmanouilides G 1980 Cardiogenic shock associated with perinatal asphyxia in preterm infants. J Pediatr 96:705

5. Cohn HE, Sacks EJ, Heymann MA, Rudolph AM 1976 Cardiovascular responses to hypoxemia and acidemia in fetal lambs. Am J Obstet Gynecol 120:817

6. Dawes GS, Mott JC, Shelley HJ 1959 The importance of cardiac glycogen for the maintenance of life in foetal lambs and new-born animals during anoxia. J Physiol 146:516

7. DeSa DJ 1979 Coronary arterial lesions and myocardial necrosis in stillbirths and infants. Arch Dis Child 54:918

8. Dock W 1946 The predilection of atherosclerosis for the coronary arteries. J Am Med Assoc 131:875

9. Donnelly WH, Bucciarelli RL, Nelson RM 1980 Ischemic papillary muscle necrosis in stressed newborn infants. J Pediatr 96:295

10. Finley JP, Howman-Giles RB, Gilday DL, Bloom KR, Rowe RD 1979 Transient myocardial ischaemia of the newborn infant demonstrated by thallium myocardial imaging. J Pediatr 94:263

11. Fisher DJ, Heymann MA, Rudolph AM 1980 Myocardial oxygen and carbohydrate consumption in fetal lambs in utero and adult sheep. Am J Physiol 238(Heart Circ Physiol 7):H399

12. Fisher DJ, Heymann MA, Rudolph AM 1981 Myocardial consumption of oxygen and carbohydrates in newborn sheep. Pediatr Res 15:843
13. Fisher DJ, Heymann MA, Rudolph AM 1982 Regional myocardial blood flow and oxygen delivery in fetal, newborn, and adult sheep. Am J Physiol 243(Heart Circ Physiol 12):H729

14. Gruenwald P 1949 Necrosis in the coronary arteries of newborn infants. Am Heart J 38:889

15. Lees MH 1980 Perinatal asphyxia and the myocardium. J Pediatr $96: 675$

16. Meschia G, Cotter JR, Breathnach CS, Barron DH 1965 The diffusability of oxygen across the sheep placenta. Q J Exp Physiol 50:466

17. Nelson RM, Bucciarelli RL, Eitzman DV, Egan EA II, Gessner IH 1978 Serum creatinine phosphokinase MB fraction in newborns with transient tricuspid insufficiency. N Engl J Med 298:146

18. Peeters LIH, Sheldon RF, Jones MD Jr, Makowski EL, Meschia G 1979 Blood flow to fetal organs as a function of arterial oxygen content. Am J Obstet Gynecol 135:637

19. Rowe RD, Hoffman I 1972 Transient myocardial ischaemia of the newborn infant: a form of severe cardiorespiratory distress in full-term infants. J Pediatr 81:243

20. Setzer E, Ermocilla R, Tonkin I, John E, Sansa M, Cassady G 1980 Papillary muscle necrosis in a neonatal autopsy population: incidence and associated clinical manifestations. J Pediatr 96:289

21. Tweed WA, Cote J, Wade JG, Gregory G, Mills A 1982 Preservation of fetal brain blood flow relative to other organs during hypovolemic hypotension. Pediatr Res 16:137

22. The authors wish to acknowledge with thanks the financial support of the Medical Research Council of Canada, the Manitoba Heart Foundation, and the Alberta Heritage Foundation for Medical Research, and the technical assistance of Mr. Wayne Pucci, Miss Maureen Cumming, and Mr. Ken Gregory, of the Anesthesia Research Laboratory, University of Manitoba, where this work was completed.

23. Address correspondence to J. M. Davies, M.D., Department of Anaesthesia Foothills Hospital at the University of Calgary, 140329 Street N. W., Calgary, Alberta, Canada, T2N 2T9.

24. Received for publication January 6, 1984

\title{
Glycosylated Hemoglobin and Plasma Protein in Newborns of Normal and Diabetic Women
}

\author{
MOHAMED M. ELSEWEIDY, HOSSAM E. FADEL, AND EDATHARA C. ABRAHAM(29) \\ Department of Cell and Molecular Biology [M.M.E., E.C.A.] and Department of Obstetrics and Gynecology \\ [H.E.F.], Maternal-Fetal Medicine Section, Medical College of Georgia, Augusta, Georgia, USA
}

\section{Summary}

The glycosylated hemoglobin (glyco $\mathrm{Hb}$ ) and the glycoprotein of the plasma were determined using affinity chromatographic techniques in cord blood and maternal blood of normal (Group I), White's Class A diabetic (Group II), and insulin-dependent diabetic (Group III) mothers. The results revealed significant increase of glyco $\mathrm{Hb}(P<0.005)$ and glycoprotein $(P<0.005)$ in the newborns of Group III mothers in comparison to those of Group I. The glyco $\mathrm{Hb}$ of maternal blood in this group also showed significant increase $(P<0.005)$ while the increase in $\mathrm{Hb}$ $A_{1}$ and plasma glycoprotein were nonsignificant. All values for cord blood and maternal blood of White's Class A diabetics revealed no significant change from the normal group. We conclude that the fetuses of insulin-dependent diabetic mothers are hyperglycemic in utero.

\footnotetext{
Abbreviations

glyco $\mathrm{Hb}$, glycosylated hemoglobin

HEPES, 4-(2-hydroxyethyl)-1-piperazineethanesulfonic acid

IDDM, insulin-dependent diabetes mellitus
}

The heterogeneity of human $\mathrm{Hb}$ has been known for some time $(7,17)$. Several chromatographically minor Hbs can be separated from adult red cell lysates using cation exchange chromatographic techniques which were designated $\mathrm{A}_{\mathrm{Ia} 1}, \mathrm{~A}_{\mathrm{Ia} 2}, \mathrm{~A}_{\mathrm{Ib}}$, and $A_{I c}$ based on their order of elution with $A_{I c}$ being the major subfraction $(19,23)$. $\mathrm{Hb} \mathrm{A} \mathrm{A}_{\mathrm{lc}}$ is formed by the reaction of the $\beta$ chain amino terminus of $\mathrm{Hb} \mathrm{A}_{0}$ (major hemoglobin) with glucose

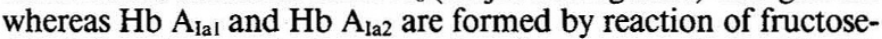
1,6-diphosphate and glucose-6-phosphate, respectively (9). Hb $\mathrm{A}_{\mathrm{Ib}}$ is a glyco $\mathrm{Hb}$ whose identity is not known. However, other glycohemoglobins that are formed by glycosylation of the $\alpha$ chain amino terminus and $\epsilon$-amino groups of certain lysyl residues on both chains are not normally separated by cation exchange chromatographic technique (25). Glycosylation of $\mathrm{Hb}$ occurs by a nonenzymatic reaction that is continuous throughout the lifespan of the red blood cell (8). It follows that glyco $\mathrm{Hb}$ levels will reflect the time-averaged blood glucose level over a period of 812 weeks $(16,20)$. This has led to increasing interest of the clinicians in the study of the glyco $\mathrm{Hb}$ levels in relation to diabetes mellitus $(14,15)$. Levels of $\mathrm{Hb} \mathrm{A}_{1}\left(\mathrm{~A}_{\mathrm{Ia}+\mathrm{b}+\mathrm{c}}\right)$ are increased in diabetes mellitus depending upon the degree of metabolic control 